\title{
Using A Smartphone Application as A Digital Key for Hotel Guest Room and Its Other App Features
}

\author{
Arnelyn M. Torres \\ Department of Tourism Management, Keimyung University \\ Daegu, South Korea \\ arnelyn.torres@gw.kmu.ac.kr
}

\begin{abstract}
The usage of smartphones is reshaping the hotel industry and smartphone applications are becoming central to hotel guests' experience. Prospective hotel guests want to make use of their own gadget such as room reservation, check-in and check-out, ordering for room service and keyless entry. To respond to these guests' demand, technological innovation is the key to enable hotel operators to stand out from the competition. Technological innovation is a key factor. This paper introduces the design and development of a mobile key for guestroom entry using a smartphone application to speed up and efficiently undergo the check-in and check-out process. Moreover, it has added features that are expected to deliver convenience to hotel guests. The drawbacks of the technological innovation were also discussed. In conclusion, the broad adaptation of mobile key entry is expected to drive positive changes in guest and host activities across the hotel industry.
\end{abstract}

Keywords: keyless entry, mobile key, check-in and check-out, plastic key cards

\section{Introduction}

The usage of smartphones are reshaping the service industry particularly the hotel business. Consumers across all demographics are using it [1]. Smartphone applications are becoming central to the hotel guest experiences as soft pillows, extra towels and a competitive price [2]. Most consumers want to make use of their Smartphones for conducting all the core functions with hotels such as checking in, making reservations, ordering room service and keyless entry [1]. In a recent survey about hotel guest satisfaction, it revealed that incorporating mobile application into a hotel stay is associated with guest satisfaction [2]. Likewise, Oracle published a hospitality report stating that $39 \%$ of hotel guests would like to use mobile technology for the check-in/check-out process [3]. Similarly, industry research recently revealed that $64 \%$ of guests expressed a desire to use their smartphone as a room key [7].

As mobile usage becomes increasingly ubiquitous for guests and to meet the challenges of growing customer expectations, the hospitality industry is turning to technology. Innovation enable hotel operators to stand out from the competition, fulfill guests' expectations and entice more customers [3]. On the other hand, an article recently published online by Intelity mentioned that mobile access at hotel empowers guest through contactless mobile technology and has the potential to improve guest experience substantially. Similarly, today's guest, particularly the Millenials have shown great appreciation for being able to use their mobile device during travel and hotel stays [10].

The Front Office is a major department in a hotel which can benefit from technology application through the use of smartphone to meet guests' expectations and improve guests' experience. A mobile application can be adopted to speed up check-in and check-out processes for guests and do away with usual guest room registration and exit.

Received (January 6, 2018), Review Result (March 8, 2018), Accepted (March 12, 2018) 
This paper introduces a novel design and development of a digital key for guestroom entry using a smartphone application. It will speed up and efficiently undergo the check-in and check-out procedure. The digital key for guestrooms is designed through innovative integration of check-in and check out procedure plus other features that is expected to deliver convenience to hotel guests.

\section{Review of Literature}

Travelers for business and leisure alike dread the antiquated check-in process at hotels. While there have been small steps to improve this, it has remained a tedious, unpleasant experiences that feels like a never ending series of questions with demands for identification cards, credit cards that ends in finally obtaining the room key [11].

Long queuing lines to check-in are common in hotels during peak time due to an exceeded amount of guest's demand. For instance, hotel guests may encounter a full lobby when checking-in during holidays. The lengthy queuing time to check-in would result to negative perceptions on hotel's service quality and reduce guest's satisfaction [6]. Therefore, hoteliers should find ways to accommodate guest check-in with speed and efficiency.

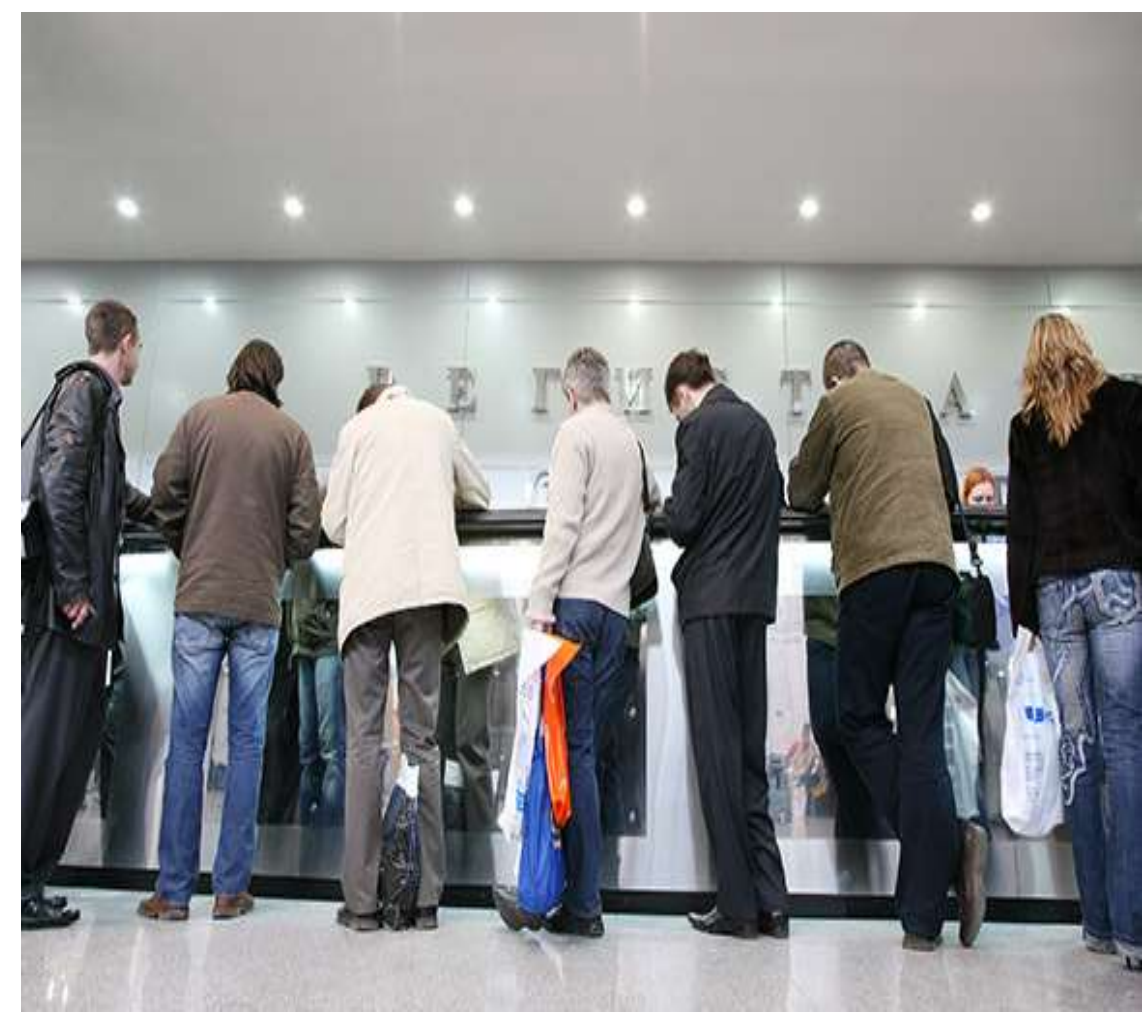

Figure 1. Waiting Line in the Hotel. (Photo from 10 Ways to Skip Lines When You Travel)

Checking in to a hotel room requires going to the front desk, showing identification and providing a credit card for room charges and incidentals. When the hotel guest's registration has been settled, he/she is given a key to the guestroom. Finally, the hotel guest is directed to his/her room or will be lead by a uniformed staff personally. The whole check-in process takes time much more when there is a long queue of guests waiting to be checked-in [4]. 


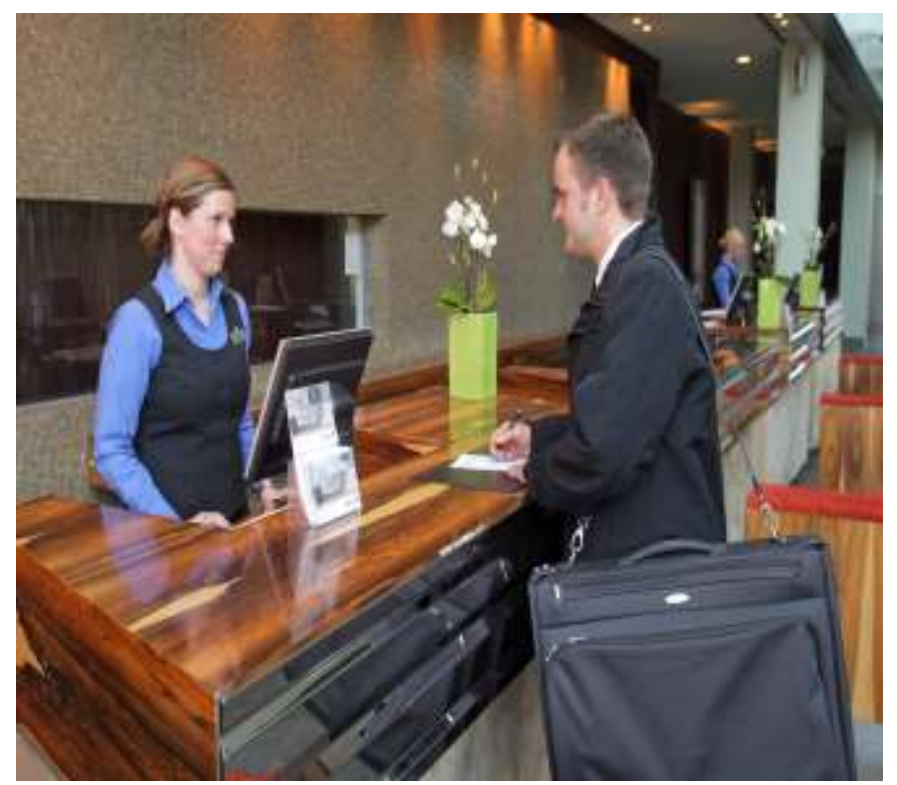

Figure 2. Guest Checking-in in the Front Desk. (Photo from Hospitality Risk Solutions)

Hotel door lock can malfunctions or key card can break down or demagnetizes and stop working, so guest had to go back to the reception and ask for help. This is quite frustrating when guests are trying to enjoy their vacation. Likewise, it can even more irritating during a business trip where business people's time is limited [13].

Plastic key cards have been in wide use with the hotel industry for decades now, and while they have proven relatively cheap and reliable, they are also prone to demagnetizing, loss, theft, and hacking. In addition, the programming and disposal of the cards takes time and resources that are fast becoming unnecessary [5].

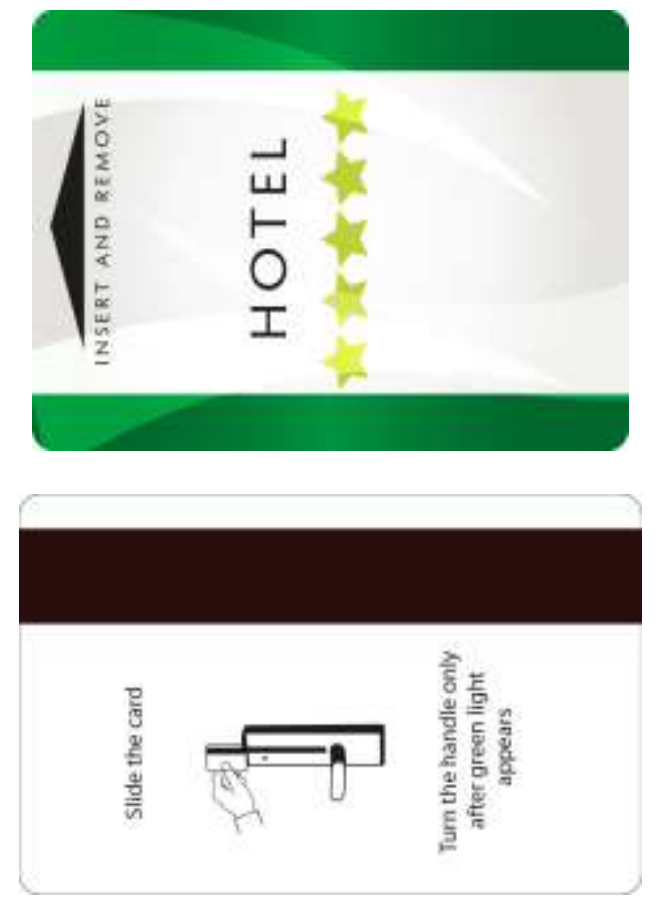

Figure 3. Plastic Key Cards (Photos from simoncards.com) 
With the above mentioned issues, hotels have thought to implement self-service technology assisted check-in. A strategy that many hotels have implemented is the selfservice applications with Self-Service Technologies (SSTs) to improve check-in and room access control. These technologies have surfaced in hotels as alternative ways for guests to check-in conveniently without any form of assistance from frontline employees [6]. Selfservice kiosks (SSKs) were adopted by some hotels to increase hotel capacity to check-in guests, hence reducing guests' waiting time and frustration caused by long queues at reception counters, while minimizing cost for hoteliers [14]. Hotel guests can opt to checkin via SSKs and obtain the activated hotel key cards without having to interact with service employees [15]. However, some drawbacks of this SSKs are some hotels guests may be uncomfortable to check-in through through SSKs because of the lack of proficiency in using technology and are afraid of making mistakes [16].

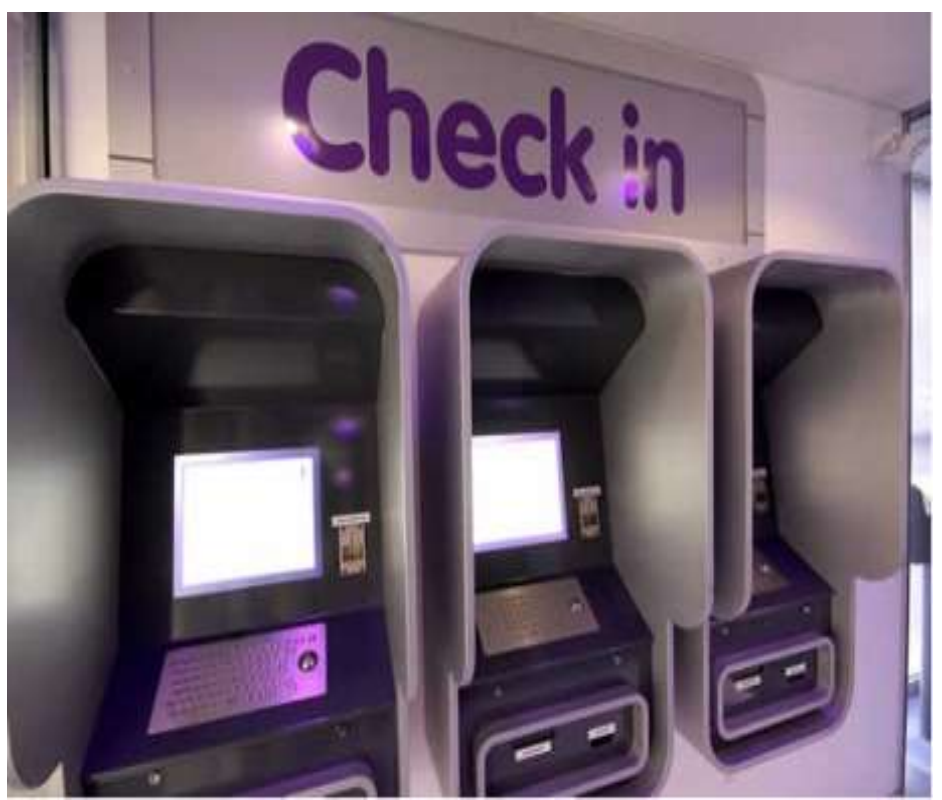

\section{Figure 4. Check-in Kiosks at Yotel (Photo from londonhotelsinsight.com)}

Hotels today should make big efforts to move away from issues previously mentioned and provide more convenient processes for their guest [11]. It is of utmost importance to meet guest's desires to ensure success in the hospitality business. Meeting guest's expectations enhances the satisfaction about the service and increases loyalty. Several researches mentioned that through shortening guests' waiting time, many advantages would be provided to the business such as improving guest satisfaction. Guests' satisfaction is reflected in the quality of operational service to minimize waiting time.

To address the gap in the literature, a novel design and development of a mobile key for guestroom entry using a smartphone application is posited to speed up and efficiently undergo the check-in and check-out process. The mobile key for guestroom is designed through innovative integration of check-in and check out process plus other features that is expected to deliver convenient and effective service to hotel guests.

\section{Digital Smart Key for Guest Room Access}

The digital key card for guest room access makes use of a (guest's) smartphone application. This adaptation of a smartphone application is appealing because guests can use their own devices that they are conversant with rather than the property having to provide additional hardware that guests might not be familiar with. Consequently, using 
guest's smartphone application keeps the cost to upgrade technology low for hoteliers and allows guests to get accustomed to it much quicker and easier [8].

Hotels can enable a guest to use their smartphone in place of a traditional keycard to lock and unlock the guest room door. In addition, it will have other features that can served as a communication tool between guest and the hotel services and facilities. The digital keycard is transmitted to the guest's device by the hotel once the booking process is complete and allows them to skip the need to stop at the front desk to receive a key, thereby reducing the overall check-in process time.

The mobile key card for hotel guest will have the following functions: (1) room checkin and out; (2) reservation booking; (3) rewards program login; (4) general hotel information; (5) digital guest feedback and comment cards and (6) hotel promos.

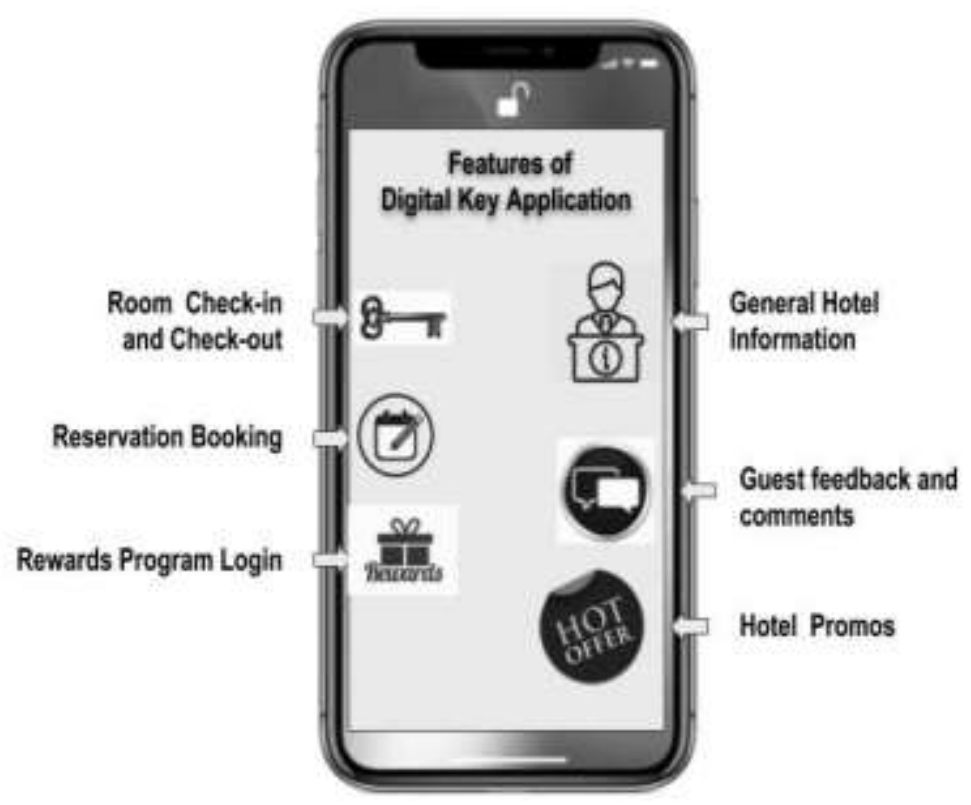

Figure 5. Features of the Digital Key Application

\subsection{Features of the Digital Key}

Room Check-In and Check-Out. On the day of their stay, guest will receive an update on when the hotel room will be available along with a room number. Once the room is ready, guests can skip the front desk, head directly to the room and open the door with the mobile key. Close to check-out time, a notification will be send to confirm check-out or extension of stay. Once the guest has checked out, the guest room access will automatically be unavailable.

Reservation Booking. Booking can be done for hotels by country, city address, point of interest. The navigation can be used to browse room features and amenities. Moreover, the feature allows the prospective guest to select the specific room in which they want to stay when they book a reservation. Additionally, it allows to pick out a room from a graphical floor plan the day before they are set to arrive, as well as order upgrades and amenities on the spot. Also, guest can save favorite hotels and room preferences for easier future bookings. Lastly, the app allows to search and book hotels available the same night.

Rewards Program Login. This feature collects the rewards points earned for every booking. Reward points can be used for room upgrade, access to special lounges, 
complimentary Wi-Fi, discounts or even free stays when booking a room or any service of participating hotels.

General Hotel Information. Hotel photos, maps, city guides and amenities can be viewed in this site. The digital key will allow guests access to various areas of the hotel property that may require a room key, such as fitness center, executive floors, elevators, parking facilities, etc.

Guest Feedback and Comments. The simplest way to get feedback is to ask for reviews within the app. The feedback and comments will be used to collect guest feedback, voice their opinions, ask for help, and engage them into the business. Hotels can ask specific questions such as rating their room amenities or service using a scale. On the other hand, the app can also ask the guest to submit ideas, issues or suggestions, and other users can vote these ideas up and down.

Hotel Promos. This feature contains hotel deals which are good to get such as last minute room deals. With this promotion, hotels can be smarter in managing their rooms on a nightly basis. Additionally, other services that are up for grabs will also be added thereby potentially increasing hotel revenues.

\subsection{Advantages of Adopting a Digital Key Entry}

The desire of travelers to have an expedited check-in experience can generate great word of mouth [5] and can result to guest satisfaction. Aside from the previously mentioned marketing advantage and guest focus strategy, there are additional reasons to consider mobile key entry. First, it saves time and money from plastic key cards. In addition, programming, tracking and replacement need not to be done. Second, it facilitates mobile check-in, saving time for both guests and staff. Next, mobile key entry systems are embedded in a hotel booking application, which guests can download easily via Online Travel Agent confirmation email or the hotel website, making rebooking easier directly through the application. Also, mobile key entry and application interact with cloud-based hotel management, which itself streamlines guest journey and business interactions, including room selection, check-in/out, upgrades and payments making monitoring of guest activities easier and easy to monitor. And lastly for security, the room is encrypted while downloaded via an application to a guest's mobile device, which has been registered with the guest's phone number, meaning that the key cannot be transferred to another device or another room [5]. In addition, the key is only active during the time the room is booked for, enabling mobile checkout and reducing interaction times [4].

Aside from the new smartphone or digital "key", the digital check-in can also help the hotel manage their inventory because guest can inform the hotel when they are arriving, which then helps the managers schedule cleanings and figure out where to place guests. By enticing users to use the mobile app for booking, hotels get more revenue. In addition, when using the digital key throughout their check-in and stay in the hotel, the Management Information System department of the hotel can gather data about guest activities. It can help by providing information about room usage and traffic patterns that can dictate cleaning, build guest preferences and eventually identify the best time to stock and what to replenish on the mini bar. As a result, the data that can be mined through the app can deliver better experience for the guest and more business opportunities for the hotels.

Finally, the digital key is also expected to reduce labor cost. Since some guests check-in late at night, hotels usually manned the front office 24 hours a day. The adoption of the digital key will lessen front desk staff who will take on night duties and will lower down the night differential expense. 


\subsection{How The Digital Key Works}

The application needs to be downloaded. The guest needs to register or enroll their phone via the application. The user should enable it to accept notifications. On the day of the arrival, guest will receive a message once checked in. Tapping on the application, an encrypted file is sent to the device with the room number and guest can head straight to their room once they get to the hotel. Since the encryption is tied to each user's phone, it makes the room secured. Moreover, since guests are connected to the hotel system, notifications can be enabled and the hotel is free to send communications while on property.

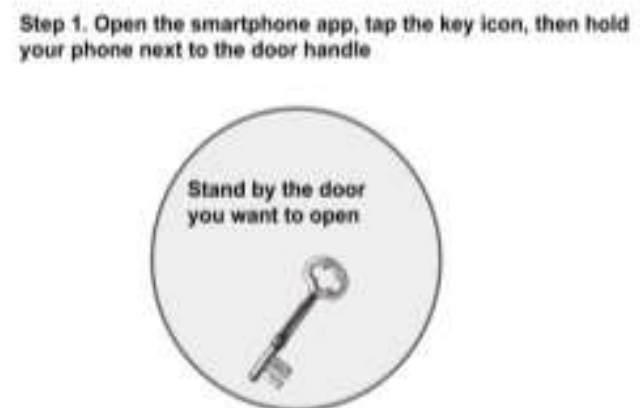

Step 2 . Teuch the circle in the opp

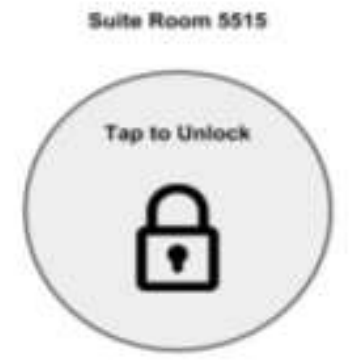

Step 3. Open your hotel room door.

Suite Room 5515

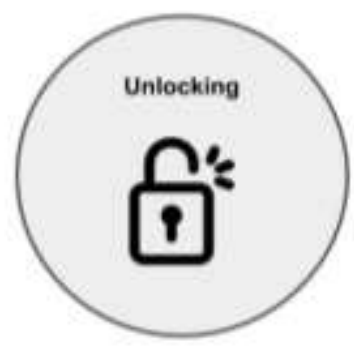

Figure 6. How Digital Key Works

The foundational technical requirements for using the mobile access is simple. First is to ensure that the door lock system is compatible with the new technology, which may necessitate door lock replacement. A major component of mobile room entry is to have a radio-frequency identification (RFID) technology. RFID technology is a key component in the Internet of Things (IoT) as a means of tagging, or identifying, physical objects on the 
IoT network [10]. The door lock maybe equipped also with Bluetooth Low Energycompatible locks [9]. Front desk staff will be assigned to create and assign digital "key cards". A special program can be made accessible to front desk staff to assign a mobile key card for a specific guest room to lock a guest's smartphone using a unique identifier, which all modern smartphones have.

The digital key card can be presented to guests through their smartphone devices in one of a variety of ways. The hotel's application can be synced to guest's smartphone once the mobile key application was downloaded. Alternatively, guest can also download a smartphone application through a third-party key vendor. A room-ready alerts can be set up to notify guests when the room is ready for check-in and also send a digital key.

\subsection{Drawbacks}

There are several drawbacks to this mobile guest room key application. First, hotel doors are already expensive and RFID enabled locks are no different. Small hotels will find costly to install the technology. Second, only one digital key is created for each room, so if guest is travelling with a spouse or friend they cannot get a key on their phone too. Still, they have to ask the front desk for a plastic key. Another is when the phone is left somewhere. A lot of personal information is available on the phone so if a thief was able to get guest's name and somehow rustle up with the guest's room number, thief can access it. Next, the technical savvy guest will have no issue sorting out the process, but for others there will inevitably be some issues along the way [12].

Leisure guests use hotel for shopping, dining and cultural explorations. They may want the opportunity to talk with frontline employees to get some quick recommendations. High end travellers prefer to be pampered when they check-in. They like to be greeted and welcomed personally as well as given the assistance while they undergo the check-in process. They may want to sit on comfortable couches and be offered coffee, soda or wine to sip while checking-in. Much more, guests' might need help with their luggage and needs to be escorted to the different parts of the property.

In-house security is of utmost concern and importance at a hotel property and thus a faceto-face encounter with guests at the front office is essential. It will eliminate allowing persons of interest to stay at the property.

\section{Conclusion}

The hospitality industry is moving toward more automated check-in systems. The adoption of technology to service guests is expected to expand rapidly. Likewise, the broad adaptation of mobile key entry is foreseen to drive positive changes in guest and host activities across the hotel industry. Cloud-based Hotel Property Management and booking application reduce hotel reliance on online travel agents, expedite booking and payment procedures and allow for remote tracking and editing of all documents and procedures. In addition, guest who feel empowered by the ability to book, check in and out and access their own rooms with autonomy and security are bound to voice great reports to their friends driving both new and repeat bookings.

Moreover, the adaptation to mobile key room entry and use of smartphone application is expected to create appetite among many consumers for more seamless travel experiences and likewise open new avenues for hoteliers to tap into. The technically equipped hotel leans towards the satisfaction of a niche market like the millenials who values the novelty of the new and wants to see how deeply technology can be implemented into the hotel stay experience. However, hotels should give the guests different check-in methods options. Some hotel guests may want the opportunity to talk with frontline employees for some quick recommendations. Other guests like to feel welcome so physical barriers between the guests and hotel staff should be removed. While some may need assistance to carry their luggages to their hotel room. This innovation may not be for every hotel but the 
technologically forward hotels may adopt this new technology however they should not forget that there is more than the speedy check-in.

\section{References}

[1] WeeklyHotels.com. (n.d.) Top 3 Trends that will shape the hotel industry in 2018. [Blog post] Retrieved from: https://blog.weeklyhotels.com/hotel-industry-trends-2018/

[2] J. D. Power, "Growth in Mobile Usage for Hotel Stays Presents Opportunity, Challenge for Hoteliers", J.D. Power Finds. Retrieved from http://www.jdpower.com/press-releases/jd-power-2017-north-americahotel-guest-satisfaction-index-study, (2017) July 12.

[3] B. Carter, "deBugged. How Technology Is Changing the Hotel Industry and the Impact On Guest Experiences. [Blog Post] Retrieved from https://www.rentokil.com/blog/how-technology-is-changingthe-hotel-industry/\#.WoNz55M-cWp, (2017) March 22.

[4] TravelUpdate, "What is hotel room keyless entry and should you use it? [Blog post]", Retrieved from https://travelupdate.boardingarea.com/what-is-hotel-room-keyless-entry-and-should-you-use-it/, (2015) August 15 .

[5] A. Gandy, Adam, “(Keyless Entry Systems are facilitating seamless hotel stay experiences)”, [Blog post]. Retrieved from http://hetras.com/post/keyless-entry-systems-are-facilitating-seamless-hotel-stayexperiences

[6] S. N. Cheong, H. C. Ling, P. L. Teh, P. K. Ahmed and W. J. Yap, "Encrypted quick response scheme for hotel check-in and access control system", Retrieved from http://journals.sagepub.com/doi/abs/10.1177/1847979017720039, (2017).

[7] M. C. Dutton, "Seeing Returns: Building Loyalty at Hotels Through Digital Customer Experience".

[8] Intelity, "Introducing Mobile Guestroom Access To Your Hotel", Retrieved from http://intelitycorp.com/main/ebook-mobile-guestroom-access/.

[9] S. Sentinel, "Use your smartphone to unlock your hotel room", Retrieved from http://www.sunsentinel.com/business/tourism/fl-keyless-hotels-20150327-story.html, (2015) March 27.

[10] Intelity, "Hotel Technology Trends: Keyless Room Entry and RFID On The Rise", Retrieved from http://intelitycorp.com/main/hotel-technology-trends-keyless-room-entry-rfid-rise/, (2016) April 10

[11] Accuant, "The Future Is Here: Mobile Check-In And Digital Keyless Entry For Hotel Are Reality", Retrieved from https://www.acuantcorp.com/future-mobile-check-digital-keyless-entry-hotels-reality/

[12] J. Meehan, "Room keys using NFC technology: benefits and drawbacks", Ehotelier the Global Portal for Hospitality Professionals, Retrieved from https://ehotelier.com/insights/2014/08/11/room-keys-usingnfc-technology-benefits-and-drawbacks/.

[13] EHL Editorial Team, "Will Digital Keys Replace Cards in Hotel Management”, EHL Blog. Retrieved from https://blog.ehl.edu/will-digital-keys-replace-key-cards-in-hotel-management, (2016) July 26.

[14] P. Avery, "Self-service check-in at hotels and motels: a guide from kiosk marketplace", Louisville, Kentucky: NetWorld Alliance, (2008), pp. 1-46.

[15] N. Ryan, "You could soon be checking into hotels with just a QR code", Retrieved from http://businessetc.thejournal.ie/jurys-hotel-group- online-booking-qr-mobile-1297222-Feb2014/, (2014) February.

[16] Kim J S, Christodoulidou N and Brewer P. 2012. Impact of individual differences and consumers' readiness on likelihood of using self-service technologies at hospitality settings. Journal of Hospitality, Tourism Res., vol. 36, no. 1, (2012), pp. 85-114.

[17] Figure [1]. 10 Ways to Skip Lines When You Travel. Photo: Hotel Front Desk via Shutterstock. Photo from https://www.smartertravel.com/2013/07/05/10-ways-to-skip-lines-when-you-travel/.

[18] Figure [2]. Hotel Industry Guest Issues: Hotel Guest Databases Such As "GuestChecker.com" Can Assist Hotel Management In Avoiding "Problem Guests" Photo from http://www.hospitalityrisksolutions.com/2010/10/20/hotel-industry-guest-issues-hotel-guest-databasessuch-as-guestchecker-com-can-assist-hotel-management-in-avoiding-problem-guests/.

[19] Figure [3] Plastic Key Cards from https://simonacards.com/en/category/Hotel-Key-Cards/

[20] Figure [4] Andrea. 2011 January. Automatic check-in: the way of the future. Photo from http://londonhotelsinsight.com/2011/01/17/automatic-hotel-check-in-the-way-of-the-future/. 
International Journal of Advanced Science and Technology Vol.113 (2018) 